\title{
EFFECT OF CURING TIME ON SELECTED PROPERTIES OF SOIL STABILIZED WITH FLY ASH, MARBLE DUST AND WASTE SAND FOR ROAD SUB-BASE
}

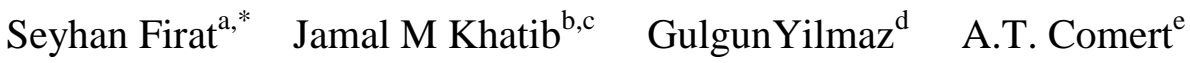

a,* Gazi University, Technology Faculty, Civil Engineering Department, 06500

Ankara, Turkey, sfirat@gazi.edu.tr

${ }^{\mathrm{b}}$ Faculty of Engineering, Beirut Arab University, Beirut, Lebanon.

j.khatib@bau.edu.lb

${ }^{c}$ University of Wolverhampton, Faculty of Science and Engineering, Wulfruna Street, WV1 1LY, Wolverhampton, United Kingdom

${ }^{\mathrm{d}}$ Anadolu University, Porsuk Vocational School, 26140, Eskisehir, Turkey, gulgunyilmaz@anadolu.edu.tr

${ }^{\mathrm{e} B i l e c i k}$ Seyh Edebali University, Bilecik Vocational School, Gulumbe Campus, Bilecik, Turkey, atcomert@gmail.com 


\begin{abstract}
The properties of sub-base filling materials in highway construction are essential as it can determine the performance of the road in service. Normally the existing materials are removed and replaced with new materials that have adequate load bearing capacity. Rising environmental concern and the new environmental legislations have made construction professionals consider other methods. Of these methods is stabilising the existing materials with other additives to improve their performance. Additives can be waste materials generated by different industries. In this work, the existing excavated soil is stabilised with waste materials. The wastes consisted of fly ash, marble dust and waste sand. The percentage addition of waste materials was $5 \%, 10 \%, 15 \%$ and $20 \%$ (by mass) of the existing soil. The soil/waste specimens were cured for $1,7,28,56,90$ and 112 days before testing. Testing included dry unit weight and unconfined compressive strength $\left(\mathrm{q}_{\mathrm{u}}\right)$ as well as XRD analysis and SEM observation. Also the California Bearing Ratio (CBR) values are obtained and reported in this investigation. The results showed that the $\mathrm{q}_{\mathrm{u}}$ values increased with the increase in waste materials content. Also there is tendency for the dry unit weight to increase with the increase in waste materials.
\end{abstract}

Keywords: California bearing ratio (CBR), unconfined compressive strength, curing time, waste sand, fly ash, marble dust. 


\section{Introduction}

Sustainable development is going to shape the future of the modern world. The consumption of virgin materials cannot be sustained at its present rate (Khatib, 2016). The primary goals of sustainable waste management are to protect human health and the environment and to conserve resources. Additional goals include prevention of the export of waste related problems into the future (e.g. 'clean' cycles and landfills) requiring little after care and socially acceptable waste management practices (Allesch and Brunner, 2014). Also many countries in the world are changing their environmental legislations by introducing taxes on virgin materials. Therefore, the construction industry is attempting to find ways to reutilize the waste generated from construction activities and other industries. This will not only contribute to waste reduction but can enhance the performance of construction materials (DiGioia et al., 1972; Temimi et al., 1998, 1991; Van den Berg, 1991, Firat et al., 2013; Kinuthia and Oti, 2013).

The impact of mismanaging the waste on the society is huge. The public health and environmental damage costs of uncollected waste, uncontrolled disposal, open burning and unsound resource recovery include additional health care costs, lost productivity, flood damage, damage to businesses and tourism and longer-term clean-up costs. Measuring these 'intangible' costs is notoriously difficult, but the evidence collected together for the Global Waste Management Outlook suggests that 
the economic costs to society of inaction are 5-10 times greater than the financial costs of proper waste management (Wilson and Velis, 2015).

Turkey is a big generator of industrial wastes resulting from various activities including quarrying and mining. Of these materials is marble dust resulting from the cutting of marble stone. There is a large reserve of marble stones in Turkey and this is associated with substantial amounts of marble dust after processing (Turkey Energy and Natural Resources 2010, Firat et al., 2012).

The power industry in Turkey relies mainly on coal to produce energy and burning coal results in the generation of bottom and fly ashes. The fly ash (FA) can be used in concrete application as partial substitution of cement in the construction industry. However, only small amounts of the 13 million tonnes of fly ash, that are generated each year, is used and most of it ends up in landfill. However, there are several potential beneficial and few harmful effects of FA application in soil. Benefits include: (i) improves soil texture; (ii) reduces bulk density of soil; (iii) improves water holding capacity; (iv) optimizes $\mathrm{pH}$ value; (v) increases soil buffering capacity; (vi) improves soil aeration, percolation and water retention in the treated zone (due to dominance of silt-size particles in FA); (vii) reduces crust formation; (viii) provides micro-nutrients like $\mathrm{Fe}, \mathrm{Zn}, \mathrm{Cu}, \mathrm{Mo}$, B etc.; (ix) provides macro-nutrients like $\mathrm{K}, \mathrm{P}$, 
$\mathrm{Ca}$, etc.; (x) reduces the consumption of soil ameliorants (fertilizers, lime); (xi) FA can also be used as insecticidal purposes and (xii) decreases the metal mobility and availability in soil. Harmful effects may include: (i) reduction in bioavailability of some nutrients due to high $\mathrm{pH}$ (generally from 8 to 12); (ii) high salinity and (iii) high content of phytotoxic elements, especially boron (Pandey and Singh, 2010).

Bruder-Hubscher et al. (2001) used bottom ash in road construction under real conditions in order to evaluate the environmental impact. Two road sections were built: One containing a sub-layer of Bottom Ash and the other was constructed using only natural gravel. Water percolating through each roadbed was collected and sampled periodically over three years. Analysis of the samples shows minimal leaching of pollutants from the bottom ash. The results are encouraging and indicate that Bottom Ash utilisation can be safe and can have an environmental impact no greater than that of natural materials.

Using fly ash in road construction by mixing it with the natural soil is highly advantageous in that it allows a greater utilisation of it and reduces the amount that is normally disposed of. It can also be used as a sub-grade chemical additive material in the road constructions. This type of use brings two benefits: (1) fly ash increases the soil strength, bearing capacity, and improve the grain size distribution while 
decreasing some geotechnical parameters such as compressibility, permeability, and swelling capacity; and (2) reduction in soil, water and air pollution (Comert et al., 2010).

Using soil with up to $30 \%$ marble slurry dust addition was found to be suitable for road construction and backfill applications (Misra et al., 2001). Gupta et al. (2002) found that the liquid limit and optimum moisture content decreased when stone dust was mixed with black cotton soil. Also the California Bearing Ratio (CBR) values were found to increase (Sabat et al., 2005). However, Stalin et al., (2004) indicated that there is decrease in plasticity when mixing marble dust with the soil. The soaked CBR values increased for soil mixed with up to $20 \%$ fly ash and $15 \%$ marble powder (by mass). However, beyond these values the CBR was found to decrease (Comert et al., 2010; Firat et al., 2012). Senol et al., (2006) found that using 10-20\% fly ash (by mass) with the natural soil caused a substantial enhancement to both the unconfined compressive strength $\left(\mathrm{q}_{\mathrm{u}}\right)$ and CBR values. These finding agree with those obtained elsewhere (Bin-Shafique et al., 2010). In addition, Bin-Shafique et al., (2010) found that using fly ash caused a decrease in the plasticity and swell potential by approximately $50 \%$ to $75 \%$. Moreover, other waste materials can be used in road sub-base. These include reclaimed highway paving materials, secondary materials, 
and construction debris that are normally disposed in landfills which can generate millions of dollars of savings to stakeholder (Cetin et al., 2010; Firat et al., 2012).

The above literature indicates that many of the waste materials may be used to improve the properties of the soil. However, there may be a concern regarding the leaching of contaminants depending upon the waste materials used. Dermatas and Meng (2003) showed that using fly ash in soil stabilisation can be effective in the immobilisation of heavy metals such as lead and chromium. This indicates that fly ash, if used in contaminated soil with lime or cement, is beneficial not only for the improvement in mechanical properties but in the positive impact on the environment through the reduction of hazardous elements in the soil.

In this study, the assessment of the strength and stiffness of base layers stabilized with Fly Ash (FA), Marble Dust (MD), and Waste Sand (WS) was carried out. These materials were added at 5, 10, 15, and $20 \%$ (by mass) to the natural soils for assessment of their possible use of in road base construction. The soil samples (with and without wastes) were cured for $1,7,28,56,90$ and 112 days in order to study the effect of curing time on soil properties. Particle size distribution, unconfined compressive strength and California Bearing Ratio (CBR) were conducted at all curing times to investigate the engineering properties of soil-waste mixtures. In 
addition XRD and Scanning Electron Microscopy (SEM) analysis were determined after 7, 28 and 112 days of curing for samples with 15\% waste (i.e. FA, MD, WS).

\section{Experimental Studies}

\subsection{Materials}

The soil material was obtained from a warehouse where Bozuyuk-Mekece Road (Turkey) was being constructed. This soil was used for road base filling materials. The waste materials used in this investigation were FA, MD and WS. The FA was obtained from Cayirhan thermal power plant in Turkey. The $\mathrm{SiO}_{2}+\mathrm{Al}_{2} \mathrm{O}_{3}+\mathrm{Fe}_{2} \mathrm{O}_{3}$ content of the fly ash is $65.50 \%$, while its $\mathrm{CaO}$ content is $14.8 \%$, thus conforming to type C fly ash according to (ASTM C 618 2005). The MD was obtained from Bilecik marble processing plant in Turkey. The marble dust was mixed with water and was collected via flocculation. To obtain a consistent sample of the MD, care was taken so that the plant constantly cuts the same type of marble and then was placed in the storage area. Table 1 presents the chemical composition of MD. Industrial waste sand is a by-product of Silica $\left(\mathrm{SiO}_{2}\right)$ that is used in glass manufacturing. Sandstone is sieved through the 500 micron sieve. The coarse particles are then used for glass production while the fine particles are disposed of as waste sand (WS). There is approximately 200,000 tons of WS generation in the Bilecik region of Turkey. The WS sample was obtained from the disposal site near Bilecik-Camis plant. 
The chemical compositions of the soil, FA, MD and WS are given in Table 1. The index properties, classification and compaction characteristics of all materials are presented in Table 2.

\subsection{Sample Preparation and Testing}

The natural soils was crushed with a rubber mallet and sieved by using No.4 (4.75 $\mathrm{mm}$ ) sieve to make them ready for use in the mixtures. The soils and wastes to be used in the mixture were dried in an oven at $110 \pm 5^{\circ} \mathrm{C}$ until constant mass is achieved. This normally took one day. All mixtures were compacted with the standard proctor energy according to TS 1900-1 (2006) and ASTM D698 (2006). The $\mathrm{q}_{\mathrm{u}}$ and dry unit weight $\left(\gamma_{\mathrm{d}}\right)$ were determined in accordance with ASTM D2166 (2006) for cured and uncured specimens. The optimum moisture content and maximum dry density values of the mixture were calculated by performing compaction tests according to procedure defined in TS 1900-1 (2006).

Within the study the test samples were prepared at the optimum water content. All of the mixtures to be used in the tests were compacted with the standard proctor energy according to TS 1900-1 (2006).

A total of 24 soil mixtures was prepared. The waste materials addition to the natural soil ranged from 5 to $20 \%$ (by weight). Soil samples were prepared and cured for 1 , 
7, 28, 56, 90 and 112 days. The dry unit weight $\left(\gamma_{d}\right)$, unconfined compression test $\left(\mathrm{q}_{\mathrm{u}}\right)$ and the CBR were determined at all curing ages and for all soil mixtures. However, the XRD and SEM analyses were determined at 7, 28 and 112 days for soil mixtures with $15 \%$ addition of FA, MD and WS.

\section{Results and Discussion}

\subsection{Particle Size Distribution}

The particle size distribution for the natural soil and soils containing a) $15 \%$ and b) $20 \%$ FA, MD and WS is presented in Figure 1. Soils with WS and MD show more content of fine particles compared with the natural soil and the soil containing FA. This is apparently due to the larger amount of clay and silt size particles in WS and MD compared with FA particles and the natural soil.

According to Guner (2011), in granular materials, when a material with finer grains is added to a material with large grains, the particle size distribution curve of the mixture appear to be between the particle size distribution of the two materials. In the particle size distribution of MD, WS and FA wastes, the percentage of fine particles (i.e. clay+silt) are 97, 75, 54\% respectively. Therefore, the incorporation of wastes has increased the content of fine particles when added to the soil. Provided that there is no chemical reaction, the particle size distribution curve of soil-waste mixtures can 
be calculated from the amounts of materials added to the mixture. Figure 1 also shows that particles enlargement for mixtures. This may be due to the occurrence of chemical reaction which can cause the particles to grow. The increase in the formation of large particles has also been reported by other researchers (Wild et al., 1996; Kinuthia, 1997; Koyuncu, 1998; Okagbue, 2007; Cömert et al., 2010; Firat and Cömert, 2011). The grading curve for the soil with 20\% MD is closer to that containing $20 \%$ WS. This may be due to the higher lime $(\mathrm{CaO})$ in the mixture.

\subsection{Dry Unit Weight $\left(\gamma_{d}\right)$}

The dry unit weight $\left(\gamma_{d}\right)$ at $1,7,28,56,90$ and 112 days is shown in Figures 2, 3 and 4 for soils containing varying amounts of FA, MD and WS respectively. One of the important factors is increasing dry unit weight for road subbase materials when waste materials are included. Hence, MD and WS are used mainly for two reasons: i) huge amount of waste left in the environment with very limited re-use and ii) to increase the dry unit weight of road subbase fill material.

As the curing time increases and the content of waste varies, there seems to be a different trend in the dry unit weight depending on the waste material used. In Figure 2, when FA is incorporated, the dry unit weight values is generally reduced, as the percentage of fly ash increases. However, there is slight change in dry unit 
weight with the increase in curing time. The long-term dry unit weight is higher than that of short-term for soil mixed with 5-15\% FA. However, at 20\% FA the dry unit weight seems to decrease with the increase in curing time. The incorporation of MD in the soil leads to a higher dry unit weight compared with those containing fly ash (Figure 3). On the other hand, there does not seem to be a clear trend in the dry unit weight with the increase in curing time. At $15 \% \mathrm{MD}$, the dry unit weight does not seem to change with curing time. However, there is an increase in the dry unit weight at 10 and $20 \% \mathrm{MD}$ addition and at $5 \% \mathrm{MD}$, there seems to be a slight variation with curing time. For soil containing WS (Figure 4), there is a noticable increase in the dry unit weight with the increase in curing time regardless of the MD content. Also the dry unit weight of soil is higher in the presence of WS compared with the soil containing FA and MD. WS has $86.7 \% \quad \mathrm{SiO}_{2}$ and therefore its dry unit weight is higher than the other waste materials. WS does not show the pozzolanic reaction with curing time.

\subsection{Unconfined Compressive Strength $\left(q_{u}\right)$}

The development of unconfined compressive strength $\left(\mathrm{q}_{\mathrm{u}}\right)$ with curing time for soils containing different additions of FA, MD and WS is shown in Figures 5 and 7 respectively. Generally and regardless of the content of waste in the soil, there is an increase in the $\mathrm{q}_{\mathrm{u}}$ with the increase in curing times. For soil containing FA, the higher 
the FA content the higher the strength. Also strength values are higher than those containing MD and WS. The values ranged from $325 \mathrm{kPa}$ at 1 day curing for the soil with $5 \%$ FA to $1000 \mathrm{kPa}$ at 20\% FA for specimens cured for 112 days. The reduction in the water content of the sample leads to a harder material and may explain the higher strength. This reduction may also be attributed to the chemical reactions between the FA particles due to the presence of calcium in its composition (Figure 5). With regard to the effect of different MD additions on the $\mathrm{q}_{\mathrm{u}}$ of soil (Figure 6), the trend is not so clear. At early ages of curing the soil containing 20\% MD displayed lower compressive strength than the other MD soil mixes. However at later days, all MD soil mixtures exhibited similar strength. Generally the inclusion of MD yield lower strength compared with the soils incorporating FA. This is because MD is not pozzolanic material itself. Soil containing 5-15\% WS showed similar strength both at early and later ages of curing (Figure 7). However, the strength at 20\% WS is similar at 1 day of curing and substantially lower at 112 days of curing compared with the other percentage additions of WS soils. Unconfined compressive strength values of all samples with mixed waste materials were changed according to curing time and $\%$ weigth of waste. The higher compressive strength in the FA mixtures may be attributed to the pozzolanic properties of the FA particles. 


\subsection{Soaked CBR}

The CBR test specimens are prepared according to ASTM D1883 (2007). Then their 4 day swelling values were recorded and the CBR test was performed on the samples according to TS 1900-2 (2006). Further details about the CBR test and a comprehensive set of CBR data at different curing ages are given elsewhere (Firat et al., 2012). The CBR values for uncured specimens and specimens cured for 28 days only are reported here and shown in Figure 8 . The soaked CBR values of the soil without any addition is $8 \%$ at both curing ages. The addition of waste materials has caused a noticeable increase in the CBR values compared with the soil without addition regardless of the curing conditions. When FA is added, the CBR is more than two and half time than that of the soil without addition. This increase is about double when MD or WS are added to the soil. At 28 days of curing, the addition of MD or WS has decreased the CBR, whereas adding FA seems to have increased the $\mathrm{CBR}$ value. But $\mathrm{CBR}$ values of $\mathrm{MD}$ did not change because it has $55 \% \mathrm{CaO}$ therefore it has shown carbonation (see XRD analysis) (Figure 8).

\subsection{Correlation between $q_{u}$ and $\gamma_{d}$}

Figure 9 (a-c) shows the correlation between the unconfined compressive strength $\left(\mathrm{q}_{\mathrm{u}}\right)$ and the unit dry weight $\left(\gamma_{\mathrm{d}}\right)$ for soil with $20 \%$ addition of FA, MD or WS. 
Generally and as can be expected, an increase in $\mathrm{q}_{\mathrm{u}}$ is associated with an increase in $\gamma_{\text {d. }}$ A linear relationship seems to describe this correlation as indicated in the values of $\mathrm{R}^{2}$ (Figure 9) obtained which range from 0.80 to 0.96 . The slope of the linear relationship is the highest when FA is present in the soil followed by soil containing MD and WS respectively. The higher slope indicates that a small increase in $\gamma_{d}$ leads to larger increase in the $\mathrm{q}_{\mathrm{u}}$.

\subsection{XRD analysis}

Figure 10 shows the XRD patterns for the natural soil (Figure 10-a) and for the FA, MD and WS (Figure 10-b). Smectite varies the values of 4.50-1.50 A. The XRD pattern clearly displays a reflection at $1.72 \AA$ representing smectite. Among the swelling clays, the most common dioctahedral smectite is montmorillonite, which has two siloxane tetrahedral sheets sandwiching an aluminium octahedral sheet (Xi et al., 2005). Smectites are specified as 2:1 layered clays and swell in water (Firat et al., 2012). Other minerals as illite, kaolin, quartz, feldspar, calcite, dolomite, opal-CT, anhydrite and hematite are shown in Figure 10-b.

Figure 11 shows XRD patterns for the soil containing $15 \%$ addition of FA, MD and WS cured for 7, 28 and 112 days. As seen in Figure 11, increasing curing times 
caused decreasing values of essential elements such as $\mathrm{Ca}, \mathrm{H}, \mathrm{O}, \mathrm{Si}$ (Bonaccorsi et al., 2005).

Tobermorite is calcium silica hydrate (CSH) mineral that is the results of reaction of silica, soil and additives (i.e. waste materials) which have calcium compound $\left(\mathrm{CaCO}_{3}, \mathrm{CaO}, \mathrm{Ca}(\mathrm{OH})_{2}\right)$. This mineral becomes more intense due to increasing curing time (Komarneni et al., 1987; Sarkar et al., 2006). Especially, FA and water reaction caused pozzolanic activity and consequently this caused decreasing effect on the kaolinite and illite clay minerals peak. Smectit and illite minerals are mainly affected for 28 and 112 days curing time (Figure 11).

\subsection{SEM Analysis}

Certain properties or factors of FA that may influence its value for the field application are grouped into positive and potentially negative categories (Adriano and Weber, 2001): (i) Positive: Calcium carbonate equivalency; especially for type C fly-ash; presence of pozzolanic reactions; dominance of silt size particles; presence of $\mathrm{Ca}, \mathrm{K}$ and other nutrients; buffering capacity; mitigation of aluminium toxicity, especially in subsoils. (ii) Potentially negative: Presence of B and soluble salts especially in unweather materials; long-term availability of Mo, Se and As; High calcium carbonate equivalency in certain products; potential micronutrient deficiency and other nutrient imbalance; potential sodicity; reduced infiltration and percolation 
in some cases; high erosivity; high economics of handling, delivery and application; restrictive regulations (Pandey and Singh, 2010).

The effect of $\mathrm{CaO}$ on the activity of mixed materials can explain the pozzolanic reaction and carbonation. Formation of cementitious material by the reaction of lime with the pozzolans $\left(\mathrm{Al}_{2} \mathrm{O}_{3}, \mathrm{SiO}_{2}, \mathrm{Fe}_{2} \mathrm{O}_{3}\right)$ in the presence of water is known as hydration of fly ash. The hydrated calcium silicate gel or calcium aluminate gel (cementitious material) can bind material together. The pozzolanic reactions for soil stabilization are as follows (TRB, 1987):

$$
\begin{aligned}
& \mathrm{CaO}+\mathrm{H}_{2} \mathrm{O} \rightarrow \mathrm{Ca}(\mathrm{OH})_{2} \\
& \mathrm{Ca}(\mathrm{OH})_{2} \rightarrow \mathrm{Ca}^{++}+2[\mathrm{OH}]^{-} \\
& \mathrm{Ca}^{++}+2[\mathrm{OH}]^{-}+ \mathrm{SiO}_{2} \rightarrow \mathrm{CSH} \\
&(\text { silica }) \quad(\text { gel }) \\
& \mathrm{Ca}^{++}+2[\mathrm{OH}]^{-}+\mathrm{Al}_{2} \mathrm{O}_{3} \rightarrow \mathrm{CAH} \\
& \text { (alumina) (gel) }
\end{aligned}
$$

For class $\mathrm{C}$ fly ash, the lime present in the fly ash reacts with the siliceous and aluminous materials (pozzolans) in the fly ash. Lime stabilization of soils occurs in a similar manner, where the pozzolanic reactions depend on the siliceous and aluminous materials provided by the soil (Senol et al., 2003). 
Figure 12 shows SEM micrographs of soil containing 15\% FA, MD and WS and cured for 112 days. The FA particles are clearly observed as round shape, and sharp edge minerals (Figure 12b) and finally 15\% FA, MD particles covered by carbonation (Figure 12b) except the $15 \% \mathrm{WS}$ particles. Intrinsic chemical reaction followed by intra-particle diffusion as chemically-controlled mechanism at the surface of $\mathrm{CaO}$. Chemical reaction of carbonation starts only after the setting period upon curing.

Figures 13 to 15 show SEM images for soil with $15 \%$ FA, MD and WS respectively. The presence of FA in the soil results in the formation of smectite, which may be due to pozzolanic reaction (Figure 13).

Soil with 15\% MD shows the presence of carbonation (see arrows in Figure 14). Smectite leafs cannot be seen due to cation change for soil containing $15 \%$ MD. Soil with WS shows high $\mathrm{SiO}_{2}$, therefore clay sheeting is observed instead of carbonation (Figure 15). Carbonation can also be seen on clay minerals. This happened due to the separation of $\mathrm{Ca}^{2+}$ ions from clay sheeting. Furthermore, the SEM images of all samples indicate that large quantities of hydrated products are forming with the increase in curing time (Firat et al., 2012). 


\section{Conclusions}

Some developing countries have made significant progress over recent decades, but both collection coverage and controlled disposal rates in the poorest countries remain at low levels. The Global Waste Management Outlook estimates that around 2 billion people worldwide still lack access to regular waste collection; while a larger number, around 3 billion, lack access to controlled disposal services for municipal solid wastes. This reality is a global public health and environmental imperative requiring a co-ordinated approach, rather than just a national or local problem. Without concerted international action, the situation is likely to get worse rather than better, as urban populations and waste quantities grow in the poorest countries (Wilson and Velis, 2015).

In this study, soil, classified as medium to low plasticity, is used to prepare mixtures. Soil is mixed with 5\%, 10\%, 15\% and $20 \%$ (by weight) of either FA, MD or WS. Samples were cured in the laboratory air at ambient temperature and humidity for 1 , 7, 28, 56, 90 and 112 days. Engineering properties, such as unconfined compressive strength $\left(\mathrm{q}_{\mathrm{u}}\right)$ and California Bearing Ratio (CBR) values were reported in this investigation. 
The results of the experimental study suggest that waste materials such as FA, MD and WS can be used for the stabilization of road sub-base filling material. This is particularly beneficial to the environment as it would reduce the use of virgin materials and using waste materials which would otherwise go to landfill. As Wilson and Scheinberg (2010) indicated that some of the technical elements are not, however, sufficient to deliver a sustainable and well-functioning integrated and sustainable waste management system. A city also needs to address three key governance strategies: inclusivity, allowing stakeholders to contribute fully as users, service providers and enablers; financial sustainability, providing services that are cost-effective and affordable; and sound institutions and pro-active policies.

The following conclusions can be drawn from the research described in this study:

1. Wastes (FA, MD, WS) can be effectively used for the road sub-base stabilization in medium and low plasticity soil.

2. Soil containing of FA caused an increase in unconfined compressed strength compared with that containing MD or WS.

3. Soil containing 5-15\% WS showed similar strength both at early and later stages of curing. However, the strength at $20 \%$ WS is similar to that of other soils with WS for the un-cured mixtures but substantially lower at 112 days of curing compared 
with the other soils containing WS. Also the CBR for soil with 20\% FA is at least 2.5 times higher than soils with MD or WS.

4. As the dry unit weight increases, the unconfined compressive strength increases. The highest rate of increase is observed in the soil with FA followed by respectively the soil with MD and WS.

5. The XRD patterns for soil containing 15\% FA, MD or WS cured for 7, 28 and 112 days shows that there is a remarkable increase of Tobermorite.

6. The SEM images indicated that all samples showed formation of reaction products depending on the curing time.

\section{Acknowledgements}

This study was completed with the support provided by Sakarya University Scientific Researches Unit (BAP/Dr-Thesis) Project numbered 2009-50-02-007; thus, the authors would like to acknowledge their gratitude to Sakarya University.

\section{References}

Adriano, DC \& Weber, JT (2001) Influence of fly ash on soil physical properties and turf grass establishment. Journal of Environmental Quality 30: 596-601. 
Allesch, A \& Brunner, PH (2014) Assessment methods for solid waste, management: A literature review. Waste Management \& Research 32: 461-473.

ASTM C618 (2005) Standard specification for coal fly ash and raw or calcined natural pozzolanic for use in concrete. Annual Book of ASTM Standards, ASTM International.

ASTM D1883 (2007) Standard Tests Method for CBR (California Bearing Ratio) of Laboratory-Compacted Soils. Annual Book of ASTM Standards, ASTM International.

ASTM D2166 (2006) Standard Test Method for Unconfined Compressive Strength of Cohesive Soil. Annual Book of ASTM Standards, ASTM International.

ASTM D698 (2006) Standard Test Method for Laboratory Compaction Characteristics of Soil Using Standard Effort. Annual Book of ASTM Standards, ASTM International.

Bin-Shafique S, Rahman K, Yaykiran M \& Azfar I (2010) The long-term performance of two fly ash stabilized fine-grained soil subbases. Resources, Conservation and Recycling 54: 666-672. 
Bonaccorsi E, Merlino S \& Kampf AR (2005) The crystal structure of tobermorite 14 $\AA$ (plombierite), a C-S-H phase. Journal of the American Ceramic Society 88: 505512.

Bruder-Hubscher V, Lagarde F, Leroy MJF, Coughanowr C \& Enguehard F (2001) Utilisation of bottom ash in road construction: Evaluation of the environmental impact. Waste Management \& Research 19: 545-556.

Cetin B, Aydilek, AH \& Guney Y (2010) Stabilization of recycled base materials with high carbon fly ash. Resources, Conservation and Recycling 54: 878-892.

Comert AT, Firat S, Yilmaz G, \& Sumer M (2010) The effect of fly ash, marble dust and waste sand on CBR and permeability of the road sub-base filling materials. $A C E-$ TRE-047, $9^{\text {th }}$ International Congress on Advances in Civil Engineering 27-30 September Karadeniz Technical University, Trabzon, Turkey.

Dermatas D \& Meng X (2003) Utilization of fly ash for stabilisation/solidification of heavy metals contaminated soils, Engineering Geology, 70: 377-394. 
DiGioia AM \& Nuzzo WL (1972) Fly ash as structural fill. J. Power Div., ASCE 98: 77-92.

Firat S, \& Cömert AT (2011) Curing time effects on CBR of stabilized kaoline with fly ash, lime and cement. Journal of the Faculty of Engineering and Architecture of Gazi University 26: 719-730.

Firat S, Yilmaz G, Comert AT \& Sumer M (2012) Utilization of marble dust, fly ash and waste sand (Silt-Quartz) in road sub-base filling materials. KSCE Journal of Civil Engineering 16: 1143-1151.

Firat S, Y1lmaz G, Vural I, Khatib JM \& Kinuthia JM (2013) Reducing Energy Requirement Using Waste Materials. in: Prof. Dr. S. Firat (ed.), II. International Workshop on Earthquake and Sustainable Materials (IWESM), Sakarya University, Technology Faculty, pp. 200-213, ISBN: 978-605-4735-07-05.

Guner MS (2011) Material Science-Construction Materials and Concrete Technology, 14. Edition, Aktif Publish, pp. 316-320 (in Turkish). 
Gupta AK, Sachan AK \& Sahoo AK (2002) Stabilization of black cotton soil using crusher dust. Proceeding of Indian Geotechnical Conference, pp. 308-310.

Khatib JM (2016) Sustainability of construction materials, Elsevier, Hardcover ISBN: 9780081009956, Woodhead Publishing.

Khatib JM (2009) Low curing temperature of metakaolin concrete. American Society of Civil Engineers (ASCE)-Materials in Civil Engineering Journal 21: 362-367. Kinuthia JM (1997) Property changes and mechanisms in lime-stabilized kaolinite in the presence of metal sulphates, Phd Thesis, School of the Built Environment, University of Glamorgan.

Kinuthia JM \& Oti JE (2013) Radical waste-based approaches towards sustainability in building and construction: Review of case studies. International Conference and Exhibition on the Application of Efficient and Renewable Energy Technologies in Low Cost Buildings and Construction (RENEWBUILD 2013), Gazi University, 16-18 September. 
Koyuncu H (1998) Stabilizasyon/solidifikasyon yöntemleriyle iyileştirilmiş petrollü sondaj atıkların fiziko-kimyasal mikro-yapısı ve geoteknik özellikleri, Phd Thesis, Osmangazi Üniversitesi, (in Turkish).

Komarneni S, Breval LE, Miyake M \& Roy R (1987) Cation-exchange properties of $(\mathrm{Al}+\mathrm{Na})$-substituted synthetic tobermorites. Clays and Clay Minerals, 35: 385-390.

Misra AK, Mathur R \& Goel P (2001) Marble slurry dust in roads- an apt solution for industrial waste. Journal of Highway Research Bulletin 65: 83-91.

Okagbue CO (2007) Stabilization of clay using wood-ash. The Journal of Materials in Civil Engineering, 19: 14-18.

Pandey, CP \& Singh, N (2010) Impact of fly ash incorporation in soil systems. Agriculture, Ecosystems and Environment 136: 16-27.

Sabat AK, Behera SN \& Dash SK (2005) Effect of fly ash- marble powder on the engineering properties of an expansive soil, Proceeding of Indian Geotechnical Conference, pp. 269-272. 
Sarkar R, Das SK, Mandal PK, \& Maiti HS (2006) Phase and microstructure evolution during hydrothermal solidification of clay-quartz mixture with marble dust source of reactive lime. Journal of the European Ceramic Society 26: 297-304.

Senol A, Bin-Shafique S, Edil TB \& Benson CH (2003) Use of class C fly ash for stabilization of soft subgrade. ARI, The Bulletin of the Istanbul Technical University, 53(1): 98-104.

Senol A, Edil TB, Bin-Shafique S, Acosta HA \& Benson CH (2006) Soft subgrades' stabilization by using various fly ashes. Resources, Conservation and Recycling 46: 365-376.

Stalin VK, Anu VJ, Kumar RS \& Srinivasan V (2004) Control of swell potential of expansive clays using solid wastes. Proceeding of Indian Geotechnical Conference, pp. $155-158$.

Temimi M, Ait-Mokhtar A, Camps JP \& Laquerbe M (1991) The use of fly ash in clay products stabilized with cement and like, obtained through extrusion, Waste Materials in Construction, 48: 451-458. 
Temimi M, Rahal MA, Yahiaoui M \& Jauberthie R (1998) Recycling of fly ash in the consolidation of clay soils. Resources, Conservation and Recycling 24: 1-6.

TRB (1987) Lime Stabilization: Reactions, Properties, Design, and Construction, State of the Art report 5. Transportation Research Board, National Research Council, Washington, DC, USA.

TS 1500 (2000) Classification of Soil for Civil Engineering Purposes, Turkish Standards Institution (TSI), Ankara.

TS 1900-1 (2006) Methods of Testing Soils for Civil Engineering Purposes in the Laboratory Part 1: Determination of Physical Properties, Turkish Standards Institution (TSI), Ankara.

TS 1900-2 (2006) Methods of Testing Soils for Civil Engineering Purposes in the Laboratory-Part 2: Determination of Mechanical Properties, Turkish Standards Institution (TSI), Ankara.

Turkey Energy and Natural Resources (TENR) (2010) Report of marble. http://www.enerji.gov.tr (accessed September 22, 2016). 
Van den Berg JW (1991) Quality and environmental aspects in relation to the application of pulverized fuel ash. Waste Materials in Construction 48: 441-450.

Wild S, Kinuthia JM, Robinson RB \& Humphreys I (1996) Effects of ground granulated blast furnace slag (Ggbs) on the strength and swelling properties of limestabilized kaolinite in the presence of sulphates. Clay Minerals 31: 423-433.

Wilson DC \& Scheinberg A (2010) What is good practice in solid waste management. Waste Management \& Research, 28(12) 1055-1056.

Wilson DC \& Velis CA (2015) Waste management-still a global challenge in the 21st century: An evidence-based call for action. Waste Management \& Research 33: $1049-1051$.

Xi Y, Frost RL, He H, Kloprogge T \& Bostrom T (2005) Modification of Wyoming montmorillonite surfaces using a cationic surfactant, Langmuir, 21: 8675-80. 